\title{
Rooting out Poverty: People, Passion, and Place at Station 20 West
}

\author{
Lisa Erickson, Isobel Findlay, Colleen Christopherson-Cote
}

\begin{abstract}
This case study summarizes and discusses our project exploring the impact of co-location, connectedness, and community-campus collaboration in addressing the root causes of poverty and our efforts to build capacities in Saskatoon. The site of this study is Station 20 West, a community enterprise centre in the heart of Saskatoon's inner city that opened in the fall of 2012 as a result of community knowledge, participation, and determination to act for the common good. We share our findings, lessons learned, and project team reflections which underscore the connectedness of poverty reduction and reconciliation, the importance of including those with lived and diverse experience in community-campus engagement (CCE), and the hallmarks of good CCE.
\end{abstract}

KEYWords poverty; community-campus engagement; decolonizing; co-location; reconciliation

\section{What We Set Out to Learn}

The authors, as part of a research team that also included co-managers of Station 20 West, two graduate students, and a second academic researcher, investigated the complex communitybased collaboration among partners at Station 20 West Community Enterprise Centre (S20W) in Saskatoon's inner city. Specifically, we were interested in the impact of co-location, connectedness, and community-campus collaboration on efforts to address the root causes of poverty and build capacities in Saskatoon. Our study, part of the larger study Community First: Impacts of Community Engagement (CFICE) funded by the Social Sciences and Humanities Research Council of Canada, aimed to understand how community-campus partnerships "can be designed and implemented to maximize the value created for non-profit, community-based organizations?" We endeavoured to answer these questions:

- How well does community-campus engagement (CCE) support innovative capacity building that can make Saskatoon more inclusive, strong, and sustainable? And how does this impact poverty reduction initiatives?

- How does co-location (sharing the same place) of partner organizations affect service, how do their different mandates affect outcomes, and how do synergies (where organizations cooperate to achieve more than they can do alone) develop among them or not?

- How does a university presence impact the Station 20 West community enterprise 
model, committed to social and economic equity through community economic development where people develop their own solutions to systemic barriers?

This case study summarizes and discusses our findings captured in our full project report. ${ }^{1}$ We first explain our approach to this community-based project which merges communityidentified principles and participatory action research methodology. We then describe the context including the city and the specific neighbourhoods surrounding our research focus: the community hub, Station 20 West. We proceed to discuss our findings and key learnings related to the three research questions. We close with team reflections about the role of people, place, and passion; the centrality of reconciliation to poverty reduction in our context; the role of those with lived experience with poverty in this work; and thoughts on disrupting linear notions of knowledge mobilization.

\section{Our Approach}

We used participatory action research in this project — aligning our decolonizing methodology with the vision and guiding principles of the Saskatoon Poverty Reduction Partnership (SPRP): "a city that bridges", "we are all treaty people", and "nothing about us, without us".2 Recognizing both how we differ and what we share-different experiences and knowledges and shared histories - from the summer of 2015 to the summer of 2016 (phase one of the project), we gathered information and input, built and shared capacity through surveys engaging people with lived experience of poverty, conducted focus groups and interviews (with S20W service users, co-locating partners, university faculty, staff, and students, and community partners), and completed a literature review. In total, this study involved 107 individuals: 70 who completed surveys, 29 who participated in focus groups, and 8 who provided interviews. The rigour of our data analysis was strengthened by the diversity of our project partners. These partners invested in an iterative process over several months that engaged students, faculty, and partners: the SPRP, S20W, and two University of Saskatchewan entities-the Community-University Institute for Social Research, which led the project, and the Office of Community Engagement and Outreach, located at S20W - as well as community members in a public forum on September 11, 2017, to share findings.

\section{Context}

Saskatoon is a city of approximately 278,500 and is the largest city in the province of Saskatchewan in Canada. The city is situated in Treaty 6 territory and the Homeland of the Métis, and a place in which colonization, including stealing land, starving communities, and

\footnotetext{
${ }^{1}$ Findlay, I.M., Sunny, S. R., del Canto, S., Christopherson-Côté, C., \& Erickson, L. Impacting community strength and sustainability: Community-campus engagement and poverty reduction at Station 20 West Community Enterprise Centre. Saskatoon: Community-University Institute for Social Research. Study participant voices reported throughout this case study are cited from that report.

${ }^{2}$ From poverty to possibility.... and prosperity: A 5 year review of the Saskatoon Community Action Plan to Reduce Poverty, Saskatoon Poverty Reduction Partnership (SPRP), February 2017. Retrieved from www.communityview.ca
} 
sabotaging families, has left indelible scars and a legacy of trauma. Despite this painful colonial legacy and ongoing reality, Saskatoon is also the site of considerable strengths and is on the front line of reconciliation efforts with 98 organizations, businesses, faith communities, and partners aligned in their commitment to truth and responding to the 94 Calls to Action identified in the Truth and Reconciliation Commission of Canada (TRC)'s report. ${ }^{3}$ The project partners identified in this case study are among the community groups committed to truth and reconciliation.

The focus of this case study is the inner city of Saskatoon, also commonly referred to as Saskatoon's Westside Core Neighbourhoods - a vibrant, gritty, and tenacious cluster of neighbourhoods plagued by staggering economic, social, educational, and health inequities.

S20W is a community enterprise centre in the heart of these neighbourhoods which opened in the fall of 2012 as a result of community knowledge, participation, and determination to act for the common good. Those actions built on community-campus collaborations that had been at the heart of grassroots community activism on quality of life and other issues since the 1990s. In addition, key institutional partners, the Saskatoon Health Region and the University of Saskatchewan, contributed to the collaborative journey that incubated Station 20 West.

When a new provincial government withdrew committed funding for the community enterprise centre in 2008, the community learned "if we come together as a group, we can make it happen." Realizing "they could be the change," they mobilized across their differences (age, gender, ethnicity, religion, for example) to raise the money to make S20W a reality. One co-locator confirmed that things might have been different:

If those thousands of people didn't come for that march, or if those kids hadn't put those pennies to those unions donating. ... I feel like we're a symbol for a social cause, social issues and social justice. . That's why there are so many of those events located here ... because they think of what S20W means to the community.

As a result of such community initiative, S20W is home to seven diverse organizations/ tenants, and serves as a hub for meetings and gatherings for several additional partner organizations that invigorate and benefit from S20W. It is for many a vital "knowledge hub" and "place of healing." Together, these community-based organizations and programs incubate collaborative, action-oriented work with partners throughout the city dedicated to improving community health and well-being.

\footnotetext{
${ }^{3}$ For over 100 years, Canada's residential school system served to undermine Aboriginal families, cultures and communities while assimilating children into settler society. The Truth and Reconciliation Commission of Canada traveled Canada to hear the stories of over 6000 people, most of whom were residential school survivors. Survivors shared experiences of being forcibly taken from their homes and experiencing physical and sexual abuse and the lasting life-, family-, and community-wide impacts of Canada's residential school system. The TRC report (2015) and related materials can be retrieved from the commission website: http://www.trc.ca/websites/trcinstitution/index.php?p=3
} 


\title{
Findings
}

\section{What did we learn about CCE and its impact in this community and on poverty reduction?}

Research Question: How well does community-campus engagement (CCE) support innovative capacity building that can make Saskatoon more inclusive, strong, and sustainable? And how does this impact poverty reduction initiatives?

Our project affirmed the centrality of relationships built on trust and reciprocity to collective community change initiatives (facilitated by organizational co-location and CCE at Station 20 West). From the perspective of participants, at the heart of effective collaboration and partnership are highly connected and integrated stakeholders who care deeply about social justice, the community, and each other. As one partner put it, they represent "a really diverse assemblage of co-locating partners" with "a thread that ties us all together, and that's social justice." Effective collaboration requires thoughtful relationship stewards, with a shared vision for positive community change and commitment to accountability to the community. "Purposively wanting to collaborate and pool some of their resources towards shared initiatives and projects," the co-locating partners aim to root out the underlying causes of poverty, including the systemic socio-economic exclusion whereby the privilege of some comes at the expense of others' impoverishment.

Our findings also directly challenge the traditional scholarly paradigm that equates research rigour with distance and disinterest. Community-campus engagement at S20W had particular "decolonizing responsibilities" in a place that one participant called "a centre of learning and reconciling." Disinterest in this context would be a denial of that responsibility and of the critical rethinking of the paradigms and practices that made research so destructive of Indigenous peoples and communities feeling "studied to death." One academic researcher insisted that supporting S20W which "is itself an intervention ... is a responsibility of researchers," while a community partner was clear that "academic research isn't worth anything unless it has a social utility or community impact." Another academic researcher challenged colleagues to reconsider the value of their research:

\begin{abstract}
We've got too many university researchers who feel that the most that they need to do is do their research and, if a little tidbit of it gets out to a practitioner or somebody who would be able to apply it, good. But they don't have any obligation to try to share information, or even work as a peer with researchers in the community to move the organization or project, or address the social issues.
\end{abstract}

The CCE activity based at Station 20 West was viewed as valuing different knowledges which serve to animate Station 20 West as a site of formal and informal learning and community organizing.

Community partners and engaged scholars are charting new, nuanced, complex, and longterm relationships that centre relevance and shift the priority to community impact rather than scholarly output, while recognizing that university-based scholars must publish to sustain their publicly funded capacity to engage with the community and connect those communities with 
globally relevant research and important conversations. Effective knowledge mobilization remains at the heart of impact and innovation notwithstanding this shift in priorities. This shift requires a commitment to learning, unlearning, and relearning, to learning from and with those with diverse experience and to recognizing the community assets and potential that can be obscured by stereotypical views. It also elevates the role and responsibility of anchor institutions ${ }^{4}$ such as the university to the prosperity of people and place.

We learned that place and space play a critical role in bringing people together to cultivate belonging and many ways of knowing, to support social and economic justice, and to facilitate perseverance while addressing the complex systemic issues underlying poverty. S20W is located in a community where many people feel rooted and connected to one another, and yet social isolation is pervasive. S20W claims and holds space for community building grounded in community assets and is aimed at building equity. Participants reflected on the role and design of physical space and the importance of an inviting, inclusive space that mirrors the diversity within the community. Equally important is a "safe space" where "those difficult questions" especially those related to intersectional power, privilege, and resources in programmatic and systemic contexts, can be asked and diverse knowledges and not only "book smarts" are valued. Working together in CCE, community and campus participants alike reported feeling mutual validation when they otherwise often feel isolated and alone in their work.

Our team deliberately held space for the voices of those with lived experience of povertyProfessors of Poverty-throughout this project, and we sincerely heed the expertise and guidance of Vanessa Charles, long-time Inclusion Advocate with the SPRP:

Professors, in general, are people who have extensive knowledge and are learned in a specific field. That knowledge has generally been gained through formal education. These professors are extremely gifted in their expertise. Professors of Poverty are equally gifted and knowledgeable, though this education is delivered through their lived experiences. They have knowledge of the complexity of poverty as it relates to their lives. This knowledge is a unique gift and cannot be replicated or taught through the use of textbooks, lectures, or even research.

A Professor of Poverty once said, "You cannot learn what my life is like by reading or taking classes, you can learn my life by crawling into my skin and living my life." Many of the Professors of Poverty had extensive knowledge of what it is like living with unsafe housing, lacking food, living with the physical and mental health limitations, the experience of family violence, and the general feeling of isolation and the inability to "fit in" with community.

It is critical in poverty reduction work to include the voices and experience of Professors of Poverty so that policies, practices, and projects reflect the actual circumstances and not the perceptions of those with no experience.

\footnotetext{
4 "Anchor institutions are enterprises such as universities and hospitals that are rooted in their local communities by mission, invested capital, or relationships to customers, employees, and vendors." See https://democracycollaborative.org/ democracycollaborative/anchorinstitutions/Anchor\%20Institutions
} 


\section{Lessons learned related to CCE and poverty reduction work}

- Creating space for people with lived experience of poverty is critical in CCE focused on reducing poverty.

- Perceptions of poverty are often rooted in stereotypes and a lack of experience with people living in poverty.

- Community members in Saskatoon's core neighbourhoods feel over-researched and disempowered by the burdens of tokenism.

- Research/project outputs must genuinely consider and incorporate community knowledges and meet community identified needs to ensure rigour and relevance.

\section{What did we learn about organizational co-location at Station 20 West?}

Research Question: How does co-location (sharing the same place) of partner organizations affect service, how do their different mandates affect outcomes, and how do synergies (where organizations cooperate to achieve more than they can do alone) develop among them or not?

The co-location model offers community members access to various organizations, strengthens involvement, and facilitates informal and formal partnership, collaboration, relationship building, and resource sharing. Our findings suggest that it is important to deliberately and intentionally nurture engagement and collaboration among co-locating partners while being explicit about roles, responsibilities, and expectations. Also, this project grew our appreciation for the complex entanglement of the parts and the whole in a colocation context, and the importance of acknowledging and planning for conflict.

Through surveys, community residents indicated that they were generally familiar with S20W and underlined its success in imparting a sense of security and belonging within the community as well as bridging the realms of community and university. One community member commented, "I feel safe here," while another concluded, "A new building the community supported and paid for. ... It matters that it belongs to the community."

Participants recommended expanding the range of services, especially for youth and people with disabilities, and promoting the remarkable story of S20W more broadly to the public. Participants also underscored the importance of thoughtful design and how a physical space impacts accessibility and community.

\section{Lessons learned related to organizational partnership and co-location}

- Synergies develop in planned and less planned, formal and informal, direct and indirect ways.

- Relationships, respect, and reciprocity are key resources to building fairness.

- Community ownership and engagement are critical to S20W success. Cultural inclusion and ceremony are critical in this community.

- Social justice is the thread that ties people together. People, Passion, and Place create a recipe for success.

- Education and learning that respects different knowledges and worldviews is the foundation to socio-economic justice. 
- The university's presence strengthens the work of community-based organizations, facilitating access to resources, education, and employment opportunities.

- The University Office and CCE is at the heart of a "culture of learning," deep listening, critical thinking, inclusive knowledge, and social innovation.

\section{What did we learn about the presence and impact of a university at Station 20 West?}

Research Question: How does a university presence impact the Station 20 West community enterprise model, committed to social and economic equity through community economic development where people develop their own solutions to systemic barriers?

The University of Saskatchewan's Office of Community Engagement and Outreach at Station 20 West (the Office) opened in 2012 when the building in which it is co-located, Station 20 West, opened. Aligned with the vision for Station 20 West, the Office focuses on building and stewarding community-campus relationships in Saskatoon's core neighbourhoods aimed at supporting social, educational, economic, and health equity through teaching, learning, research, and artistic work. The Office's staff, including a manager and administrative support (2FTE), function in a host of roles including buffer, bridge, broker, as well as guest, host, and ambassador. The Office's institutional home within the University and its reporting lines have changed multiple times since opening, and it has resided within Advancement and Community Engagement, the Office of the Vice-President Research. and currently University Relations.

In reflecting on the role of the university, people found it difficult to speak only about the Office. Indeed, some people argued that evaluating the Office meant evaluating how well the University resourced, supported, and promoted the Office.

Our findings encourage reflection on several ongoing institutional and cultural challenges to CCE. Participants mused about the university's inconsistent support and long-term commitment to CCE. They frequently mentioned that university policies and procedures are not structured to enable and recognize CCE, resulting in time-consuming and distracting "work-arounds" for collaborators. These "work-arounds" sometimes relate to the allocation and distribution of project resources including the difficulty in resourcing non-campus partners and doing so equitably and expeditiously. This is frustrating for community partners and a test of their patience amidst their work on pressing community issues. We suggest such policies may impede CCE work and penalize scholars and partners who engage in CCE.

CCE stakeholders also observed collisions between the lived experience of people in the Core Neighbourhoods, with the privilege that often accompanies traditional academic success (especially when unexamined and undeclared). These collisions are both avoidable and navigable with the support and stewardship of specialized units like the Office. Similarly, dedicated CCE units serve to navigate and translate, helping to ensure that research is relevant, and that engagement and knowledge mobilization is relevant to and accessible for communities. At its best, community members attested to the CCE activities of the Office and its campus partners that helped "[them] think more deeply about [their] work," changed their thinking about the theory-practice binary, and foregrounded "a caring kind of profile to the University." Having diverse stakeholders be heard confirmed people's sense that "research is 
an important part of changing community."

\section{Lessons learned related to a university's place in community engagement, equity, and growth}

- Managing effectively the multiple roles—buffer, bridge, guest, host, and ambassador —of the Office is key to CCE success.

- Resourcing, supporting, and promoting the Office and community-based research is a critical responsibility of the university.

- There is a foundation of trust, relationship building, and capacity building at the heart of this innovation to build strong, sustainable communities.

- CCE often shines a light on what shapes people's lives in the Core neighbourhood, helps attract investment in the community (eg. institutional procurement and leveraging institutional reputation to access funding for community initiatives), and highlights educational, employment, and other community development possibilities.

- CCE helps people understand the Core and creates opportunities for the Core to learn about itself.

- CCE makes the university easier to understand and seem more accessible.

- The Office pushes boundaries in overt, covert, and creative ways that sustain critical thinking, expand educational opportunities, and design new strategies to meet social needs.

- The Office mentors for "solidarity-making or ally work" were at the heart of good CCE at S20W.

- The Office helps people navigate university bureaucracy, ethical issues, power imbalances, and a culture that undervalues the rigour of community-based research.

\section{Team Reflections on our Project Learning Journey}

People, passion and place are at the centre of collaboration that positively impacts community.

As a team, we felt compelled to articulate and reflect back to participants three themes that emerged as we listened and digested the data in this study. We heard clearly that prioritizing people and relationships is at the centre of effective CCE and collaborative co-location aimed at building equity and poverty reduction. Similarly, we heard that effective CCE aimed at reducing poverty must involve passion, rigour, and commitment- that it's critical to engage minds and hearts and that one without the other affects impact. Last, from the traditional lands upon which we work, to how spaces are designed and animated, place and space is inextricably connected to and shapes collaborative work. 


\section{People}

Relationships make this work possible.

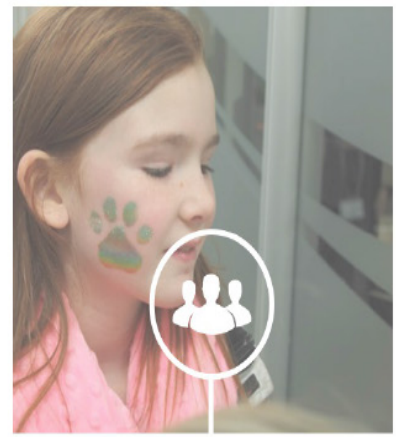

Passion

To have impact we must engage the mind and the heart.

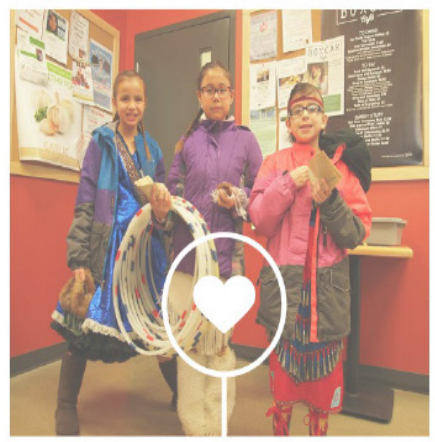

Place

Location and space matter.

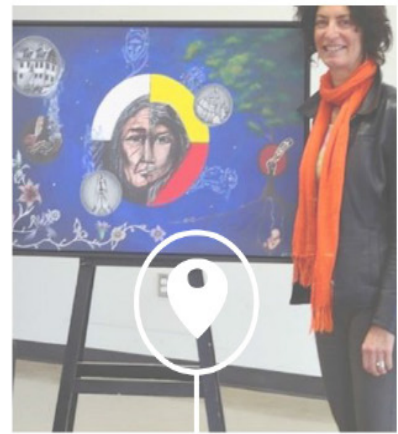

Without reconciliation, there can be no end to poverty.

During the course of this project, the TRC released the Calls to Action. This intensified our decolonizing methods and guided thinking about systemic factors that need to be addressed in poverty reduction and elimination work. The Calls to Action made clear that ending poverty is about ending discrimination, and addressing the systemic barriers that reproduce inequality and poverty that disproportionally affect Indigenous peoples.

We continue to depend on the expertise of those with lived and diverse experience, but institutions make it hard to recognize and support them adequately or appropriately.

As project partners, we continue to struggle with the inequitable value placed on knowledge acquired outside of formal education; however, this project amplified our commitment to institutional changes to better recognize and support the knowledge keepers and expertise that is vital to meaningful and relevant community inquiry.

Impactful CCE aligns with community identified needs and opportunities, authentically engages communities, accurately reflects community input, and crafts outputs that hold meaning for and relevance to communities.

Project outputs valued in postsecondary contexts, constrained by disciplines disconnected from the larger social context, are seldom as useful in the broader community. Our experience throughout this project reminded us that community-based projects are devoid of impact if focused energy is not dedicated to bi-directional knowledge mobilization throughout the lifecycle of the project — challenging typical unidirectional notions of knowledge mobilization (research disseminated to community).

Community-campus engagement at Station 20 West is part of the reconciliation journey.

As partners of Reconciliation Saskatchewan, we are committed to the shared vision of creating an interdependent and fair society based on truth, justice for past wrongs, space for learning, representation, fairness and sovereignty. 


\section{About the Authors}

Colleen Christopherson-Cote is the coordinator for the Saskatoon Poverty Reduction Partnership and co-lead for the Evaluation and Analysis working group of CFICE. She lives in Saskatoon, Treaty 6 Territory and the Homeland of the Métis. She catalyzes, convenes and coordinates community collaboratives, drives change, and works to improve her community.

Lisa Erickson (corresponding author) is the manager of the University of Saskatchewan's Office of Community Engagement and Outreach at Station 20 West, serves as co-chair of the Saskatoon Poverty Reduction Partnership, and CFICE project collaborator and working group member. She focuses on CCE that strengthens relationships and communities, and reduces inequities. Email: Lisa.erickson@usask.ca

Isobel Findlay is a professor emerita, Edwards School of Business, University Co-Director, Community-University Institute for Social Research, University of Saskatchewan, and a member of the Community Campus Engage Canada (CCEC) Working Group, CFICE. She hopes to see decolonizing and Indigenizing efforts that effect real culture change, knowledge democracy, and social and cognitive justice. 